\title{
INFLACIÓN CREDENCIALISTA Y HETEROGENEIDAD PRODUCTIVA EN LA ECONOMÍA PARAGUAYA
}

\author{
Credential Inflation and Productive Heterogeneity in the Paraguayan Economy
}

\author{
Luis Ortiz, Dr. C. \\ Escuela de Altos Estudios en Ciencias \\ Sociales, Paris \\ https://orcid.org/0000-0002-1902-8834 \\ lortiz@icso.org.py
} Palabras claves: Mercado de Trabajo, Heterogeneidad Estructural, Estructura Productiva,
Educación, Credencialismo.

Keywords: Labor Market, Structural Heterogeneity, Productive Structure, Education, Credentialism.
Recibido: 23 de octubre de 2019

Aceptado: 19 de febrero de 2020

\section{RESUMEN}

En el marco de las transformaciones económicas propias de la globalización y del mundo del trabajo asociadas, se planteó este estudio a los efectos de analizar y explicar la contradicción entre el aumento de la población con diplomas del sistema educativo en Paraguay y la reducida competitividad de la fuerza laboral, es decir, sus bajos niveles de competencia, su baja remuneración media, así como su inserción preponderante en ramas de actividad de baja innovación y lento crecimiento. El estudio tiene un corte cuantitativo descriptivo, basado en información de fuentes secundarias (encuestas de hogares y cuentas nacionales). Con la información analizada, se establecieron las características de la estructura productiva durante el periodo cuando el mayor acceso educativo no desembocó mecánicamente en el aumento del acceso al empleo formal y el bienestar social en el país. La principal conclusión es que la contradicción entre la masificación educativa y la baja productividad media de la economía constituye la base de la desigual distribución de los recursos y las oportunidades en la estructura social paraguaya, persistiendo las principales causas de la exclusión y la pobreza.

\begin{abstract}
Within the framework of the economic transformations characteristic of globalization and the associated world of work, this study was proposed for the purpose of analyzing and explaining the contradiction between the increase of the population with diplomas of the educational system in Paraguay and the reduced competitiveness of the labor force, that is to say, its low levels of competence, its low average remuneration, as well as its predominant insertion in branches of activity of low innovation and slow growth. The study has a descriptive quantitative cut, based on information from secondary sources (household surveys and national accounts). With the information analyzed, the characteristics of the productive structure were established during the period when greater educational access did not mechanically lead to increased access to formal employment and social welfare in the country. The main conclusion is that the contradiction between the mass education and the low average productivity of the economy is the basis of the unequal distribution of resources and opportunities in the Paraguayan social structure, with the main causes of exclusion and poverty persisting.
\end{abstract}




\section{INTRODUCCIÓN}

En Paraguay, el mercado laboral se divide en dos sectores: por una parte, un sector formal donde se emplea una reducida minoría de trabajadores que accede a puestos de trabajo con ingresos adecuados, con seguridad social, seguro de salud y jubilación, mientras que, por otra parte, un sector informal donde se emplea la mayoría de la población trabajadora, sin ingreso mínimo, sin seguridad social y en situación de vulnerabilidad ante los riesgos de la economía.

La necesidad de acceder a evidencias sobre la relación entre educación y empleo que tome en cuenta tanto los procesos objetivos -de mediano plazo-, así como las perspectivas de los sujetos involucrados, permitiría el análisis de los factores que inciden en el mercado de trabajo limitando seriamente el incremento y la homogeneidad de las productividades económicas.

En este marco, la proporción de esas limitaciones está asociada a las características de la escolarización en la sociedad, así como a los factores socioculturales que condicionan, tanto el compromiso de los trabajadores con el desarrollo económico como la responsabilidad de los propietarios para invertir en emprendimientos que redunden en el acceso al empleo y en el incremento progresivo de la competitividad en todos los sectores y ramas de la economía.

Este estudio busca identificar los factores que inciden en el perfil educacional de la población paraguaya, entendido éste como la distribución de los niveles educativos en la estratificación socioocupacional, según atributos sociodemográficos como el sexo y la edad. Del perfil educativo dependen en efecto las capacidades productivas y las chances de acceso al empleo, así como el desarrollo de la productividad económica general.

La estructura productiva, a su vez, establece marcos restrictivos y márgenes de maniobra a los sujetos para avizorar su inserción laboral, asumir costos y decidir sobre su trayectoria, dado que, como consecuencia de una larga historia de atraso y rezago, la economía constriñó el acceso a condiciones laborales adecuadas y asegurar la retribución al mérito del esfuerzo y la formación. En efecto, la escasa y dispersa inversión de capital para lograr la expansión del sector formal del mercado laboral no otorga los incentivos para apuntalar la calidad del sistema educativo.

Las preguntas que orientaron el estudio fueron: ¿Qué efecto tiene el sistema educativo en el acceso a puestos del sector formal del mercado de trabajo? ¿Qué alcances y límites presentan los actuales perfiles de egreso de la educación media y de la educación superior para la estructura económica? ¿Qué demandas y expectativas laborales tiene la población trabajadora que dispone de elevadas credenciales educativas?

La hipótesis de trabajo es que el sistema educativo dispone de una capacidad formativa circunscripta sólo a la fuerza laboral del segmento informal del mercado de trabajo.

Carnoy (1986) indica que, si bien la inversión educativa apunta a contribuir con el crecimiento económico, así como generar igualdad de oportunidades, ambos objetivos dependen de la expansión y el gasto educativo que estará más ligado al valor simbólico de la educación que a cualquiera de los efectos en el crecimiento económico, en la movilidad social o en la distribución del ingreso que se espera de la educación. Según dicho autor, las repercusiones financieras de la inversión dependerán más de las políticas educativas de expansión que de los efectos económicos esperados directamente de la educación.

Como refieren Brunet y Böcker, las características estándares de la estructura productiva en una época y una circunscripción de la economía de mercado, ligada a una institucionalidad pública específica del capitalismo del Estado de bienestar, se centran en la relación entre formación y trabajo regulada por el modelo de la cualificación, entendida como un atributo del factor trabajo y cuyo valor se estima por su productividad relativa traducida en el salario. La relación formación-trabajo está, en este modelo, constituida de mediaciones sociales que desembocan en una estructura ocupacional, con escalas salariales y jerarquías sociales (Brunet y Böcker, 2014).

La cualificación tiene un carácter social dado que depende del proceso de desarrollo de cada sociedad según la relación entre sus sistemas educativos (formación) con las estructuras del mercado laboral (trabajo), con sus instituciones de regulación laboral y sus modelos de organización ocupacional (Grootings, 1994).

Esta concepción indica el carácter situado de la cualificación, válida para ciertas ramas económicas y grupos ocupacionales en función del consenso social, así como el carácter datado, es decir ajustada según los cambios de la estructura productiva y del mercado de trabajo.

Esta concepción de la cualificación implica el carácter convencional de las clasificaciones ocupacionales y profesionales entre los distintos sectores sociales y responde a un conjunto de criterios de valoración del trabajo, por lo tanto, como un hecho social histórico. 
El sistema de evaluación de la cualificación se traduce así en el título educativo o credencial que opera como medio de verificación objetivo para los empresarios. Las credenciales son la certificación institucionalizada del conocimiento en un sistema de clasificación que vincula la formación, el trabajo y la remuneración. Las credenciales cobran la forma de títulos estandarizados, que sirven también como referencia para el reconocimiento social, es decir, como "mérito".

Ahora bien, esta cualidad de las credenciales se relativiza en procesos en que la expansión del acceso a la educación no está acompañada con la expansión del acceso al trabajo. Al sostenerse durante un periodo prolongado este desfasaje, el mercado ajusta la sobreoferta diplomada y la subdemanda remunerada con la elevación de los umbrales educativos de contratación, es decir, aumentando las exigencias y criterios de cualificación.

Cuando la composición de la estructura económica se sostiene sobre ramas de actividad con altos niveles de productividad, pero bajos niveles de absorción de la fuerza laboral (producción agropecuaria intensiva), o bien, en ramas de actividad con bajos niveles de productividad y que absorben elevada cantidad de trabajadores, la capacidad productiva de la población económicamente activa, en su conjunto, tiende a ser reducida (Berry, 2010).

Por lo tanto, cuando la demanda laboral es baja y la productividad opera de manera heterogénea, la expansión del acceso a la educación no necesariamente redunda en la expansión de capital humano porque la baja inversión de capital y el limitado alcance de la protección social en la población trabajadora, tienden a segmentar el mercado de trabajo, facilitando el acceso a los mejores puestos y a las mejores retribuciones sólo a un sector social, con altas calificaciones educativas que se insertan en los nichos de mayor productividad, mientras los demás sectores no obtienen o ven estancado el retorno a su inversión educativa (Cortés, 2016).

La heterogeneidad estructural con la dispersión y asimetría de las productividades, desemboca en un mercado de trabajo segmentado. El problema de los trabajadores pobres no reside tanto en sus deficiencias como en la estructura segmentada del mercado de trabajo; los espacios y condiciones de trabajo cuentan más que las características de los trabajadores (McConnell y Brue, 2007).

En Paraguay, la característica principal del mercado de trabajo es su desigual dualidad, con un sector informal conformado por un notorio contingente de trabajadores independientes que destinan su fuerza laboral al autosustento sin trabar relaciones laborales salariales, que dispone sólo en una baja proporción de credenciales medias y elevadas, mientras que la mayor parte está conformada por la fuerza laboral de baja formación y reducida productividad.

Con la masificación del acceso a la educación, como resultado de la reforma educativa de los años noventa, el mercado de trabajo tomó la apariencia de una mayor calificación, pero apenas una cohorte después de culminada dicha reforma, empezó a visualizarse las características propias del credencialismo: la extensión de la escolarización repercutió en el incremento de los años de estudio de la población económicamente activa, elevando la proporción de categorías sociales con escolaridad pero parte importante de ésta en ocupaciones precarias y subocupación (Ortiz, 2016)

En términos del método, este estudio movilizó un abordaje cuantitativo recurriendo a fuentes secundarias: encuestas de hogares y cuentas nacionales. Dicho análisis involucró un nivel descriptivo, a través de tablas y gráficos, de la estructura del mercado laboral y de las características educativas de la población económicamente activa. Además, se planteó un análisis con variables múltiples que permitieron distinguir los factores principales de la situación del mercado de trabajo.

\section{DESARROLLO}

\section{La población económicamente activa y la estructura productiva}

Durante las dos décadas del periodo comprendido entre los años 1997 y 2017, la economía paraguaya presentó una tendencia de crecimiento del producto, estabilidad macroeconómica y reducción relativa de la pobreza, que influyó en la participación de la fuerza laboral y delineó la evolución de su participación en cada una de las ramas de actividad económica.

Como puede verse en el cuadro 1, dos tendencias marcadas se desenvuelven en lo que a la participación laboral de la PEA ocupada respecta: por un lado, el aumento en las zonas urbanas y, por otro lado, el marcado aumento de la participación laboral femenina. Este proceso acompaña el crecimiento tanto de la población en edad laboral, así como la tendencia de la economía paraguaya en el periodo. 
Cuadro 1. Evolución de la PEA ocupada según área de residencia y sexo, años seleccionados.

\begin{tabular}{cllr|r|r|c|}
\hline Variable & Característica & \multicolumn{1}{c}{$\mathbf{1 9 9 7}$} & $\mathbf{2 0 0 2}$ & $\mathbf{2 0 0 7}$ & $\mathbf{2 0 1 2}$ & \multicolumn{1}{c}{$\mathbf{2 0 1 7}$} \\
\hline \multirow{2}{*}{ PEA } & Ocupada & $2,002,266$ & $2,223,388$ & $2,624,416$ & $3,166,113$ & $3,285,722$ \\
\hline \multirow{2}{*}{ Area } & Urbana & $1,129,760$ & $1,187,035$ & $1,505,846$ & $1,939,468$ & $2,073,598$ \\
\cline { 2 - 7 } & Rural & 872,506 & $1,036,353$ & $1,150,808$ & $1,307,436$ & $1,212,124$ \\
\hline \multirow{2}{*}{ Sexo } & Hombres & $1,291,076$ & $1,409,253$ & $1,621,763$ & $1,910,271$ & $1,971,517$ \\
\cline { 2 - 7 } & Mujeres & 711,190 & 814,135 & $1,034,891$ & $1,336,633$ & $1,314,205$ \\
\hline \hline
\end{tabular}

Fuente: Dirección General de Estadística, Encuestas y Censos - Encuestas de hogares 1997-8, 2002, 2007, 2002

Así, la población económicamente activa ocupada del país experimentó un incremento en la magnitud poblacional ocupada del orden del 64\% en el lapso de 20 años, en contraste con el crecimiento de la economía en el mismo período, del 198\%, según datos del Banco Mundial (2017).

En términos de las tasas de crecimiento de la oferta en el mercado laboral nacional, el total de la población económicamente activa en el período analizado ha tenido un comportamiento variable con tasas positivas excepto en el área rural, como se puede observar en el cuadro 2, sobresaliendo las tasas de crecimiento del área urbana y de las mujeres.

\begin{tabular}{|c|c|c|c|c|c|c|}
\hline Rama de Actividad económica & Sexo & 1997 & 2002 & 2007 & 2012 & 2017 \\
\hline \multirow{2}{*}{ Agricultura, Ganadería, Caza y Pesca } & Hombres & 473,231 & 624,604 & 552,031 & 582,518 & 486,937 \\
\hline & Mujeres & 101,856 & 169,157 & 243,306 & 307,193 & 202,255 \\
\hline \multirow{2}{*}{ Industrias manufactureras } & Hombres & 191,624 & 163,254 & 248,351 & 243,936 & 281,530 \\
\hline & Mujeres & 77,787 & 85,077 & 92,593 & 111,761 & 113,624 \\
\hline \multirow{2}{*}{ Electricidad, Gas y Agua } & Hombres & 11,406 & 13,016 & 161,577 & 16,201 & 14,046 \\
\hline & Mujeres & 2,118 & 686 & 1,559 & 3,192 & 1,347 \\
\hline \multirow{2}{*}{ Construcción } & Hombres & 112,571 & 124,785 & 355,991 & 193,260 & 275,894 \\
\hline & Mujeres & 1,256 & 2,517 & 289,538 & 1,736 & 6,024 \\
\hline \multirow{2}{*}{ Comercio, Restaurantes y Hoteles } & Hombres & 24,142 & 292,424 & 87,537 & 462,326 & 502,475 \\
\hline & Mujeres & 26,039 & 260,907 & 17,641 & 402,482 & 433,048 \\
\hline \multirow{2}{*}{$\begin{array}{l}\text { Transporte, Almacenamiento y } \\
\text { Comunicación }\end{array}$} & Hombres & 74,747 & 74,603 & 57,248 & 125,441 & 94,867 \\
\hline & Mujeres & 9,303 & 12,692 & 39,441 & 17,128 & 18,063 \\
\hline \multirow{2}{*}{ Finanzas, Seguros e Inmuebles } & Hombres & 48,676 & 52,243 & 201,102 & 95,246 & 119,543 \\
\hline & Mujeres & 23,574 & 32,507 & 405,983 & 70,274 & 71,796 \\
\hline \multirow{2}{*}{$\begin{array}{l}\text { Servicios sociales, comunales y } \\
\text { personales }\end{array}$} & Hombres & 185,435 & 171,550 & $\mathrm{~s} / \mathrm{d}$ & 251,898 & 272,461 \\
\hline & Mujeres & 275,304 & 337,622 & $\mathrm{~s} / \mathrm{d}$ & 493,630 & 535,399 \\
\hline Total & & $1,639,069$ & $2,417,644$ & $2,753,898$ & $3,378,222$ & $3,429,309$ \\
\hline
\end{tabular}

La distribución geográfica de la PEA ocupada da cuenta de un marcado crecimiento de la participación laboral en zonas urbanas y un crecimiento más bien modesto correspondiente a las zonas rurales. Según se constata en el gráfico 1 , las zonas rurales acompañan el crecimiento de la PEA ocupada hasta el año 2012, para posteriormente "perder" cerca de noventa y cinco mil personas empleadas o activamente buscadoras de empleo. 


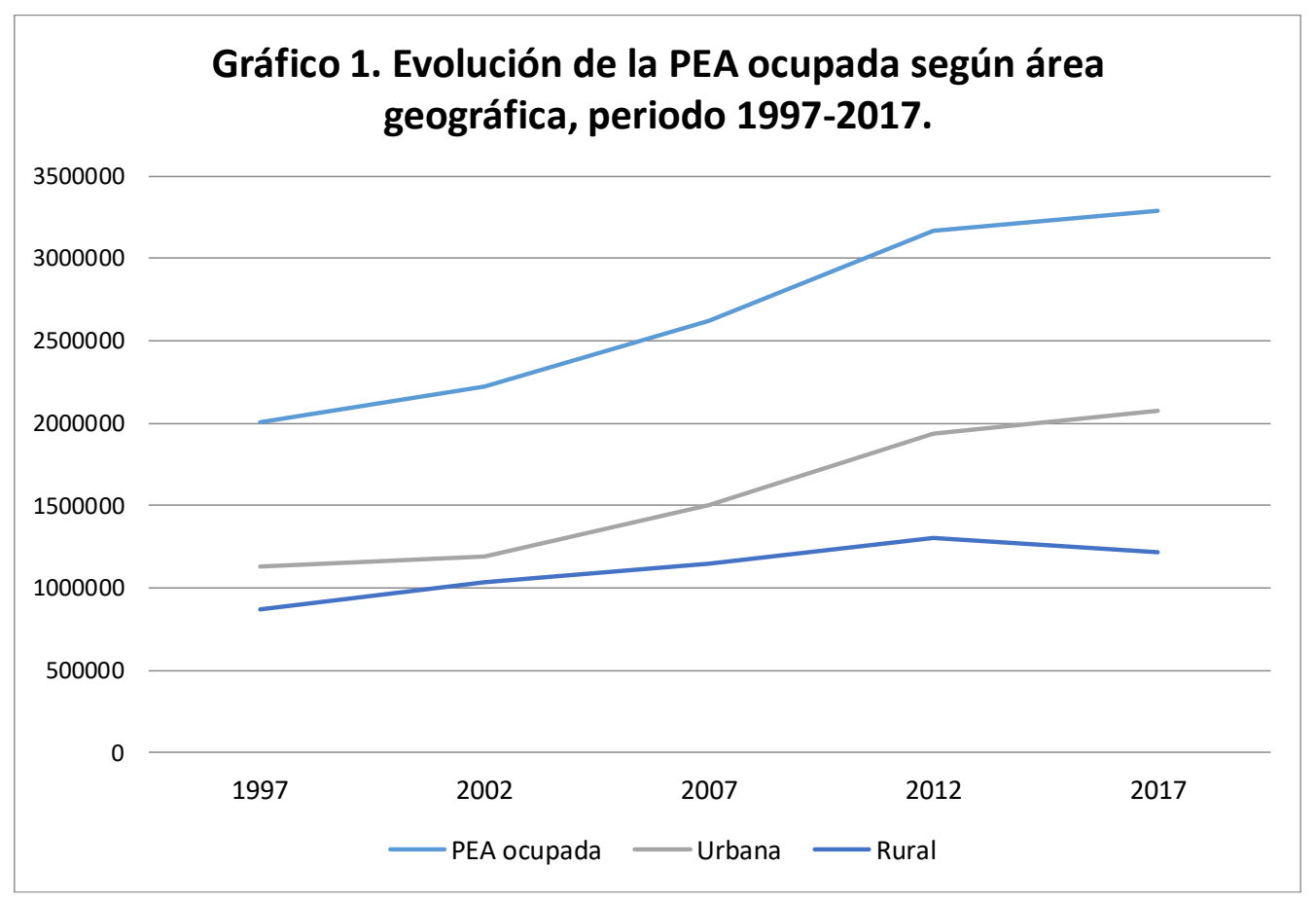

Fuente: Elaboración propia con base en encuestas de hogares 1997-2017, DGEEC.

Como refieren Goetz y Vázquez, esta tendencia responde a un proceso de urbanización que a partir de los años en que inicia el periodo de nuestro análisis, involucró a un extendido espacio geográfico, allende las históricos -y únicasregiones de urbanización, a saber, Asunción y Ciudad del Este.

"A partir de la década del 2000, esta situación (el reducido peso de las ciudades en la organización del espacio) comienza a cambiar con el surgimiento de un nuevo proceso de urbanización, que llega también al interior del país: este espacio asiste a una reconfiguración profunda de su estructura y organización urbana.

El rol socioeconómico de los centros urbanos se ve totalmente modificado y las ciudades ad-quieren una nueva significación en la vida de la población y en sus aspiraciones urbanas. Aunque no se produce un marcado incremento del peso demográfico, éstas experimen tan cambios profundos de sus funciones, lo que las vuelve dinámicas y muy atractivas. (...) en menos de quince años (a partir de los años 2000, hasta la actualidad), la red urbana para $\neg$ guaya (entendida ésta a través del protagonismo y la importancia funcional de cada ciu $\neg d a d)$, se ha visto más alterada que en el último siglo." (Goetz y Vázquez, 2014, p. 12).

Este proceso se inscribe en cambios que conciernen la estructura económica y la estructura social, cuyo abordaje requiere la atención de las interrelaciones para entenderlo en una perspectiva de la totalidad de las transformaciones socioeconómicas de la sociedad paraguaya.

En este tenor, otra dimensión que experimentó cambios en la población trabajadora y su condición de ocupación fue el género.

En términos de la variación de la población económicamente activa ocupada según el sexo, se verifica un crecimiento sostenido de la participación laboral de las mujeres, quienes pasaron de una proporción del $36 \%$ en 1997 al $40 \%$ en 2017. Ahora bien, como se observa en el gráfico 2, a pesar del incremento de la participación femenina en todo el periodo de análisis, éste fue marcado y sostenido, sobre todo, entre los años 1997 y 2012, para disminuir levemente entre los años 2012 y 2017.

Varios son los factores que explican este aumento, entre ellos los cambios demográficos tales como la intensificación de la urbanización, la migración interna, la reducción de la fecundidad, el aplazamiento de la maternidad, la posposición de la nupcialidad, el aumento de la esperanza de vida, la disminución del tamaño medio de los hogares; transformaciones socioculturales como el incremento de los hogares con jefatura femenina, el aumento significativo de la escolarización y titulación universitaria de las mujeres, su mayor participación política (CEPAL, 2013). 
Como refiere Serafini, "muchos hogares no logran satisfacer sus necesidades con el ingreso del hombre, por lo cual se hace imprescindible la participación de la mujer como proveedora de un ingreso más. (...) A pesar de que, por ello, su situación no pasa automáticamente a ser igual que la del hombre, el mismo sistema capitalista crea las bases para debilitar el patriarcado cuando, al deprimir el ingreso masculino, empuja a la mujer al trabajo remunerado" (Serafini, 2016, p. 215).

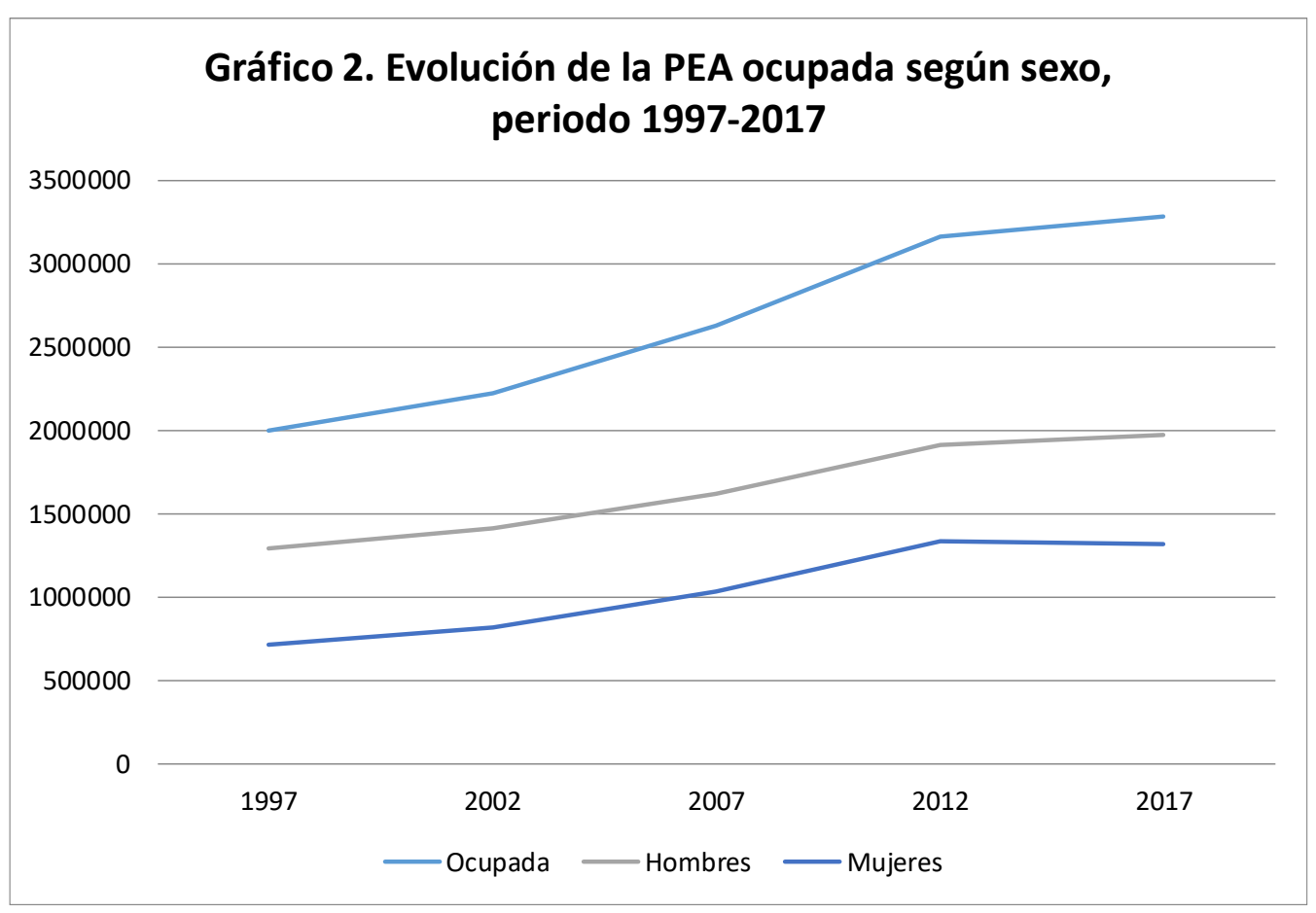

Fuente: Elaboración propia con base en encuestas de hogares 1997-2017, DGEEC.

En el apartado a continuación veremos la distribución de la población ocupada según las ramas de actividad económica para el periodo de referencia correspondiente a los años 1997 y 2017. En el mismo haremos una primera revisión de los cambios que operaron en la estructura socioeconómica paraguaya en el periodo de estudio, analizando las características de la economía según sus sectores económicos y las tendencias del desempeño de la fuerza laboral en su seno en el transcurso de dos décadas.

La tendencia del mercado laboral paraguayo en el periodo de dos décadas, entre 1997 y 2017, fue del aumento de la participación laboral, con la nota de que la participación laboral femenina se ha mantenido estable entre los años 2012 y 2017 mientras que la participación laboral de trabajadores masculinos fue progresivamente creciente.

La distribución de la población ocupada se caracterizó por el hecho que entre los años 1997 y 2002 el nivel de participación laboral de trabajadores residentes en zonas urbanas era marginalmente superior a la participación laboral de trabajadores residentes en zonas rurales. Sin embargo, a partir del 2002, la brecha ha ido aumentando considerablemente hasta decrecer incluso la magnitud absoluta de participación laboral en zonas rurales desde el año 2012.

En lo que respecta la distribución por sexo de la población ocupada, la única rama de actividad económica en que la participación femenina es mayor a la masculina, de manera consistente, es la de Servicios sociales, comunales y personales. En consonancia con lo expuesto al final del apartado anterior, la inserción progresiva de las mujeres al mercado laboral se da como una conjunción compleja entre el aumento de sus condiciones de autonomía personal y de formación profesional, con la pérdida relativa del poder adquisitivo de los ingresos masculinos durante los periodos de crisis.

Por lo general, la inserción con menores restricciones de las mujeres en el mercado de trabajo se da en las actividades de servicios, de donde a su vez despuntan otras modalidades de participación laboral con progresivos niveles de cualificación, remuneración y responsabilidad (CEPAL, 2012). 
Cuadro 4. Población económicamente activa por ramas de actividad económica según periodos etarios, periodo 1997-2017.

\begin{tabular}{|c|c|c|c|c|c|c|}
\hline Rama de Actividad Económica & Perfil etario & 1997 & 2002 & 2007 & 2012 & 2017 \\
\hline \multirow{3}{*}{ Agricultura, Ganadería, Caza y Pesca } & Adolescente & 98,618 & 146,690 & 137,585 & 122,853 & 66,469 \\
\hline & Joven & 83,014 & 124,282 & 115,116 & 115,271 & 83,682 \\
\hline & Adulto & 343,608 & 459,999 & 471,759 & 555,932 & 463,365 \\
\hline \multirow{3}{*}{ Industrias manufactureras } & Adolescente & 26,629 & 24,556 & 27,381 & 24,920 & 17,386 \\
\hline & Joven & 52,791 & 44,700 & 70,632 & 69,158 & 73,336 \\
\hline & Adulto & 178,006 & 172,285 & 227,647 & 250,723 & 289,743 \\
\hline \multirow{3}{*}{ Electricidad, Gas y Agua } & Adolescente & 836 & 268 & 11,524 & - & \\
\hline & Joven & 781 & 1,509 & 31,252 & 2,402 & 179 \\
\hline & Adulto & 11,673 & 11,925 & 115,714 & 15,643 & 14,722 \\
\hline \multirow{3}{*}{ Construcción } & Adolescente & 5,255 & 9,462 & 53,402 & 15,458 & $\overline{18,936}$ \\
\hline & Joven & 22,237 & 22,989 & 122,333 & 26,426 & 61,191 \\
\hline & Adulto & 85,377 & 91,700 & 441,006 & 147,895 & 192,376 \\
\hline \multirow{3}{*}{ Comercio, Restaurantes y Hoteles } & Adolescente & 63,838 & 67,265 & 2,900 & 69,474 & 56,097 \\
\hline & Joven & 96,244 & 104,164 & 22,936 & 182,811 & 201,523 \\
\hline & Adulto & 324,700 & 353,926 & 77,009 & 575,712 & 644,682 \\
\hline \multirow{3}{*}{$\begin{array}{l}\text { Transporte, Almacenamiento y } \\
\text { Comunicación }\end{array}$} & Adolescente & 2,778 & 5,369 & 3,388 & 2,879 & 657 \\
\hline & Joven & 11,100 & 15,635 & 24,850 & 32,809 & 16,593 \\
\hline & Adulto & 68,844 & 64,787 & 76,364 & 98,894 & 92,618 \\
\hline \multirow{3}{*}{ Finanzas, Seguros e Inmuebles } & Adolescente & 5,489 & 2,495 & 39,767 & 2,776 & 2,154 \\
\hline & Joven & 15,367 & 22,085 & 108,699 & 53,719 & 36,027 \\
\hline & Adulto & 50,557 & 57,762 & 445,277 & 104,865 & 149,441 \\
\hline \multirow{3}{*}{$\begin{array}{l}\text { Servicios sociales, comunales y } \\
\text { personales }\end{array}$} & Adolescente & 52,547 & 49,385 & - & 35,839 & 32,317 \\
\hline & Joven & 104,218 & 118,130 & - & 136,825 & 131,156 \\
\hline & Adulto & 294,444 & 331,457 & - & 555,558 & 625,493 \\
\hline Total & & $1,998,951$ & $2,302,825$ & $2,626,541$ & $3,198,842$ & $3,270,143$ \\
\hline
\end{tabular}

Fuente: Dirección General de Estadística, Encuestas y Censos - Encuestas de hogares 1997-8, 2002, 2007, 2002, 2012, 2017. Elaboración propia.

En lo que concierne al rango etario de la población económicamente activa, de su participación laboral por ramas de actividad, se observa en el cuadro 3 que el principal nicho de ocupación laboral de la población de entre 10 y 17 años de edad (adolescente), es la agricultura, donde sobrepasa incluso la participación de población joven, de entre 18 y 29 años de edad, durante casi todo el periodo, salvo entre el 2012 y el 2017, donde se verifica una situación inversa.

El rango etario de población adulta, de entre 30 y 64 años de edad, encabeza -como es de esperarse- la participación laboral en todas las ramas de actividad económica del periodo, pero en sus propias tendencias, el número de trabajadores disminuye en el periodo de 2012-2017, lo que atendiendo que el producto de dicha actividad aumentó, conlleva un aumento de su productividad por la introducción de capital y su consecuente expulsión de fuerza laboral.

Como indican Borda et al., (2015) los jóvenes han reducido su participación laboral (en el periodo 2002-2012), en especial los jóvenes varones de las zonas rurales, mientras que no hubo variaciones relevantes en la participación laboral de las jóvenes mujeres, sean éstas de zonas urbanas o rurales, de modo que el aumento de la participación laboral femenina se dio sobre todo entre las mujeres adultas. "La tendencia decreciente de la actividad laboral juvenil se relaciona con, entre otros factores, la retención de los jóvenes en el sistema educativo. El creciente aumento del número de jóvenes (hombres y mujeres) que 'solo estudian' (...), tendría una importante incidencia en la caída de la participación laboral de los jóvenes" (Borda, González y García, 2015, p. 17).

El periodo de análisis de estos autores, de menor extensión al periodo de este estudio, da cuenta empero de una tendencia que constatamos en el apartado anterior. En efecto, como veremos más adelante, la impronta del sistema educativo en las características de la participación laboral es crucial ya que con las políticas de extensión de la escolaridad (masificación educativa) desde los años noventa, una proporción de la población que anteriormente hesitaba entre el trabajo y la formación, se retiró a dar continuidad a su escolarización, aunque considerando la estratificación social, este hecho acaeció predominantemente en sectores sociales intermedios o de las fracciones superiores de las clases desfavorecidas (Ortiz, 2014).

La característica de la población económicamente activa ocupada según nivel de ingresos en la ocupación principal (Cuadro 4), revela la proporción marcadamente superior de población que se aglutina en el rango de ingresos menor a 1 millón de guaraníes, indistintamente de qué rama de actividad se trate. El rango entre 1 y 2 millones de guaraníes de ingresos supera únicamente al rango de ingreso menor a 1 millón de guaraníes en el año 2007, en la rama de Comercio, Restaurantes y Hoteles. 
Ahora bien, aunque el nivel medio de salarios del mercado laboral paraguayo, para todas las ramas de actividad económica -salvo la de Agricultura, Ganadería, Caza y Pesca-, es cercano al salario mínimo, en el transcurso de los años fueron surgiendo crecientes oportunidades para trabajadores calificados en ramas de actividad pujantes, particularmente en nichos competitivos (aun aislados) de mercado.

\begin{tabular}{|c|c|c|c|c|c|c|}
\hline Rama de Actividad Económica & Nivel de ingreso & 1997 & 2002 & 2007 & 2012 & 2017 \\
\hline \multirow{5}{*}{ Agricultura, Ganadería, Caza y Pesca } & De 0 a 1.000 .000 & 552,968 & 758,030 & 698,923 & 749,018 & 517,780 \\
\hline & $\begin{array}{l}\text { De } 1.000 .001 \mathrm{a} \\
2.000 .000 \\
\end{array}$ & 14,472 & 19,249 & 63,861 & 94,154 & 97,203 \\
\hline & $\begin{array}{l}\text { De } 2.000 .001 \mathrm{a} \\
4.000 .000\end{array}$ & 4,267 & 8,762 & 20,022 & 25,962 & 49,635 \\
\hline & $\begin{array}{l}\text { De } 4.000 .001 \mathrm{a} \\
6.000 .000\end{array}$ & 2,580 & 1,716 & 4,243 & 8,190 & 9,959 \\
\hline & Más de 6.000 .000 & 800 & 6,004 & 8,288 & 12,387 & 14,885 \\
\hline \multirow{5}{*}{ Industrias manufactureras } & De 0 a 1.000 .000 & 234,880 & 207,515 & 199,051 & 127,195 & 104,118 \\
\hline & $\begin{array}{l}\text { De } 1.000 .001 \mathrm{a} \\
2.000 .000 \\
\end{array}$ & 24,870 & 30,905 & 107,239 & 154,085 & 132,930 \\
\hline & $\begin{array}{l}\text { De } 2.000 .001 \mathrm{a} \\
4.000 .000\end{array}$ & 6,784 & 7,248 & 26,033 & 60,475 & 124,982 \\
\hline & $\begin{array}{l}\text { De } 4.000 .001 \mathrm{a} \\
6.000 .000 \\
\end{array}$ & 1,461 & 1,766 & 5,216 & 8,135 & 21,490 \\
\hline & Más de 6.000 .000 & 1,416 & 897 & 3,405 & 5,807 & 11,634 \\
\hline \multirow{5}{*}{ Electricidad, Gas y Agua } & De 0 a 1.000 .000 & 5,617 & 5,421 & 98,523 & 405 & 1,319 \\
\hline & $\begin{array}{l}\text { De } 1.000 .001 \mathrm{a} \\
2.000 .000\end{array}$ & 4,663 & 3,392 & 49,392 & 5,079 & 952 \\
\hline & $\begin{array}{l}\text { De 2.000.001 a } \\
4.000 .000 \\
\end{array}$ & 2,594 & 3,258 & 10,350 & 5,351 & 4,848 \\
\hline & $\begin{array}{l}\text { De 4.000.001 a } \\
6.000 .000 \\
\end{array}$ & 650 & 851 & 2,991 & 1,954 & 3,100 \\
\hline & Más de 6.000 .000 & & 780 & 1,880 & 6,604 & 5,174 \\
\hline \multirow{5}{*}{ Construcción } & De 0 a 1.000 .000 & 97,897 & 110,931 & 378,847 & 44,961 & 51,538 \\
\hline & De 1.000 .001 a & 12,363 & 12,376 & 194,712 & 100,992 & 115,956 \\
\hline & $\begin{array}{l}\text { De } 2.000 .001 \text { a } \\
4000 \text { ח }\end{array}$ & 3,210 & 2,987 & 49,063 & 40,806 & 94,238 \\
\hline & $\begin{array}{l}\text { De } 4.000 .001 \mathrm{a} \\
6.000 .000\end{array}$ & 357 & 256 & 11,672 & 4,223 & 11,758 \\
\hline & Más de 6.000 .000 & & 752 & 11,235 & 4,014 & 8,429 \\
\hline \multirow{5}{*}{ Comercio, Restaurantes y Hoteles } & De 0 a 1.000 .000 & 427,398 & 469,355 & 35,988 & 392,229 & 338,232 \\
\hline & $\begin{array}{l}\text { De } 1.000 .001 \mathrm{a} \\
2.000 .000\end{array}$ & 53,660 & 57,512 & 44,847 & 307,257 & 291,670 \\
\hline & $\begin{array}{l}\text { De } 2.000 .001 \text { a } \\
4.000 .000\end{array}$ & 15,229 & 21,654 & 19,587 & 126,045 & 239,165 \\
\hline & $\begin{array}{l}\text { De } 4.000 .001 \text { a } \\
6.000 .000\end{array}$ & 3,426 & 2,382 & 1,758 & 21,932 & 41,153 \\
\hline & Más de 6.000 .000 & 2,097 & 2,428 & 2,998 & 17,345 & 25,303 \\
\hline \multirow{5}{*}{$\begin{array}{l}\text { Transporte, Almacenamiento y } \\
\text { Comunicación }\end{array}$} & De 0 a 1.000 .000 & 57,429 & 59,941 & 33,619 & 32,833 & 14,279 \\
\hline & $\begin{array}{l}\text { De } 1.000 .001 \mathrm{a} \\
2.000 .000 \\
\end{array}$ & 19,676 & 20,491 & 44,733 & 60,645 & 28,013 \\
\hline & $\begin{array}{l}\text { De } 2.000 .001 \text { a } \\
4.000 .000\end{array}$ & 3,043 & 5,477 & 15,726 & 38,063 & 51,081 \\
\hline & $\begin{array}{l}\text { De } 4.000 .001 \mathrm{a} \\
6.000 .000\end{array}$ & 3,066 & 1,008 & 7,487 & 4,771 & 13,073 \\
\hline & Más de 6.000 .000 & 836 & 378 & 5,124 & 6,257 & 6,484 \\
\hline \multirow{5}{*}{ Finanzas, Seguros 3 Inmuebles } & De 0 a 1.000 .000 & 44,686 & 52,162 & 353,361 & 40,492 & 25,981 \\
\hline & $\begin{array}{l}\text { De } 1.000 .001 \mathrm{a} \\
2.000 .000 \\
\end{array}$ & 14,373 & 20,825 & 197,751 & 66,422 & 52,394 \\
\hline & $\begin{array}{l}\text { De } 2.000 .001 \text { a } \\
4.000 .000 \\
\end{array}$ & 8,631 & 7,799 & 45,594 & 34,838 & 75,770 \\
\hline & $\begin{array}{l}\text { De } 4.000 .001 \mathrm{a} \\
6.000 .000\end{array}$ & 2,520 & 2,048 & 6,931 & 13,518 & 17,808 \\
\hline & Más de 6.000 .000 & 2,040 & 1,916 & 3,448 & 10,250 & 19,386 \\
\hline \multirow{5}{*}{$\begin{array}{l}\text { Servicios sociales, comunales y } \\
\text { personales }\end{array}$} & De 0 a 1.000 .000 & 385,665 & 405,446 & $\mathrm{~s} / \mathrm{d}$ & 282,257 & 260,052 \\
\hline & $\begin{array}{l}\text { De } 1.000 .001 \mathrm{a} \\
2.000 .000\end{array}$ & 60,493 & 82,450 & $\mathrm{~s} / \mathrm{d}$ & 254,018 & 218,957 \\
\hline & $\begin{array}{l}\text { De } 2.000 .001 \mathrm{a} \\
4.000 .000\end{array}$ & 12,226 & 18,367 & $\mathrm{~s} / \mathrm{d}$ & 168,531 & 241,257 \\
\hline & $\begin{array}{l}\text { De } 4.000 .001 \text { a } \\
6.000 .000\end{array}$ & 1,350 & 1,644 & $s / d$ & 27,881 & 60,827 \\
\hline & Más de 6.000 .000 & 1,005 & 1,265 & $\mathrm{~s} / \mathrm{d}$ & 12,841 & 26,796 \\
\hline Total & & $2,090,698$ & $2,417,644$ & $2,763,898$ & $3,378,222$ & $3,429,609$ \\
\hline
\end{tabular}

Fuente: Dirección General de Estadística, Encuestas y Censos - Encuestas de hogares 1997-8, 2002, 2007, 2002, 2012, 2017. Elaboración propia.

Entre los años 1997 y 2017 la expansión del rango salarial más elevado (superior a 6 millones de guaraníes) significó un aumento de 18 veces en la rama de Agricultura, Ganadería, Caza y Pesca, así también un aumento de 12 veces en la rama de Comercio, Restaurantes y Hoteles, como 27 veces en la rama de Servicios sociales, comunales y personales. Como se verá más adelante, estas ramas constituyen aquellas con mayor participación en el producto, con la rama de Industrias manufactureras, la que experimentó asimismo un aumento en el periodo, pero no de las mismas magnitudes. 
Según Albert Berry, este proceso responde a la complejidad de la economía paraguaya que, aun con ciclos de crecimiento marcado del producto, no tuvo correlatos redistributivos, por lo que es un crecimiento "no saludable excluyente", caracterizado por el aumento del valor agregado en ramas económicas que absorben poco empleo, mientras que aquellas con altos niveles de ocupación laboral, por lo general conformadas microempresas y pequeñas empresas, retribuyen con magros ingresos a los trabajadores (Berry, 2012, pp. 35-36).

En general este rasgo lo comparten tanto las ramas de actividad del sector primario como del sector terciario de la economía, donde la producción marginal de valor agregado es baja en comparación al sector secundario (industria).

En términos de los ingresos por rama de actividad económica se destaca el hecho del marcado aumento de las medias de ingresos en las ramas correspondientes a Electricidad, Agua y Gas, por una parte, la de Finanzas, Seguros e Inmuebles por otra, y la de Transporte, Almacenamiento y Comunicaciones, por la suya, todas con aumentos acentuados, a saber, del $409 \%$, $315 \%$ y $265 \%$, respectivamente.

Resulta también significativo que la media de ingresos de las ramas de actividad económica correspondientes a Electricidad, Agua y Gas, por un lado, la de Financias, Seguros e Inmuebles por el otro, la de Transporte, Almacenamiento y Comunicaciones también y, finalmente, la de Construcciones, superan el salario mínimo legal vigente establecido en julio de 2017, a saber, de dos millones cuarenta y un mil ciento veintitrés guaraníes (Gs. 2.041.123).

En términos de la participación de la PEA ocupada según el nivel de estudios en las diferentes ramas de actividad económica, la de Finanzas, Seguros e Inmuebles es donde predomina la mayor proporción con nivel universitario. En las demás ramas de actividad económica predomina la participación de trabajadores con nivel de instrucción primaria, lo que da cuenta de la baja cualificación demandada y asociada a la baja remuneración ya referida.

Ernesto Schielfelbein ya constataba para inicios del 2000 que las ocupaciones de mayores ingresos medios y con mayores niveles educativos representaban las de los profesionales y operadores técnicos, conjuntamente con la de los trabajadores de oficina y otros (Shiefelbein, 2007, p. 183) Ambas ocupaciones características de la rama de actividad de Finanzas y otros, así como de otras de menor retribución relativa que ésta pero igualmente importantes como la Electricidad, Agua y Gas, así como la de Comercio, Restaurantes y Hoteles.

Dada las inequidades entre ramas y entre ocupaciones, se dio un incremento en general de los niveles de calificación de la fuerza laboral, según lo cual los trabajadores de cuatro ramas de actividad ya superan cómodamente la media de 9 años de estudio -conclusión de la educación escolar básica- entre los años 2012 y 2017.

La distribución porcentual de la PEA según el nivel educativo y rama de actividad económica (Cuadro 5) expresa en su evolución entre el año 1997 y 2017 cinco principales rasgos. En primer lugar, la población con sólo dos primeros ciclos de educación primaria en su haber, tanto en la rama de agricultura, ganadería, caza y pesca como en la rama de la construcción, fue disminuyendo en el periodo, mientras aumentó la del tercer ciclo de la educación escolar y, especialmente, la población con educación secundaria y educación superior, variaciones cuyo mayor ímpetu fue en el año 2012, cuando acababa de regresar de la educación superior la primera cohorte de la reforma educativa que inició en el año 1993, reforma que significó saltos cualitativos para los sectores sociales desfavorecidos aun si comparativamente con otros sectores su mejoramiento educativo no implicó el acceso a oportunidades sociales consistentes.

En segundo lugar, las ramas de actividad cuyas poblaciones respectivas al inicio del periodo contaban con bajos niveles de escolarización en la educación media y en la educación superior, dieron un salto cualitativo fueron las ramas de la industria manufacturera así como la de comercio, restauración y hotelería: la población con educación media en ambas aumentó en alrededor el 50\% mientras que la población con educación superior aumentó en la rama industrial en más del $300 \%$ y en la rama comercial en poco más del $200 \%$, lo que indica un aumento relativo de su competitividad. En la primera, el año 2012 fue decisivo en su expansión, mientras que, para la segunda, dicha expansión ya tuvo lugar desde el año 2007.

En tercer lugar, las ramas de transporte, almacenamiento y comunicaciones, por un lado, la de servicios comunales, sociales y personales por el otro, ya contaban en el inicio del periodo con una proporción elevada de población que disponía de educación media y educación superior, de modo que, como era de esperase, incrementaron su dotación de credenciales. Ahora bien, ambas ramas evolucionaron de modo diferente: mientras la rama de transporte y otros contó en todo el periodo con mayor proporción de población con educación secundaria, la rama de servicios comunales y otros atravesó por un proceso inverso, es decir, la proporción de población con educación superior fue de más elevada y mantuvo esa tendencia hasta el 2017. 
Así también, la rama de finanzas, seguros e inmuebles, del sector terciario de la economía cuenta con la mayor proporción de población económicamente activa con educación superior, lo que indica que constituye el sector con mayor competitividad, pero también el que concentra en mayor volumen las retribuciones al trabajo. En esta rama, como se verá más adelante, es donde se congregaron las categorías socioocupacionales medias y elevadas, constituyendo uno de los pívots del mercado laboral y la estructura económica.

Finalmente, la rama de electricidad, gas y agua presenta su particularidad: la primera es que la caída de la proporción de la PEA con educación secundaria fue abrupta en el periodo pasando a menos de la mitad entre 1997 y 2017, así como abrupto fue el aumento de la PEA con educación superior, pasando a alcanzar casi el doble en el periodo. Sin embargo, esta rama es en términos demográficos muy reducida, por lo que el peso en la estructura económica general de su composición y cambio no es comparable con otras ramas.

\begin{tabular}{|c|c|c|c|c|c|c|c|}
\hline $\begin{array}{c}\text { Rama de Actividad } \\
\text { Económica }\end{array}$ & Nivel de estudio & 1997 & 2002 & 2007 & 2012 & 2017 & $\begin{array}{c}\text { Media } \\
\text { poblacional }\end{array}$ \\
\hline \multirow{5}{*}{$\begin{array}{c}\text { Agricultura, Ganadería, } \\
\text { Caza y Pesca }\end{array}$} & Primaria & 89 & 80 & 75 & 72 & 66 & 76 \\
\hline & Escolar Básica & 8 & 13 & 15 & 17 & 17 & 14 \\
\hline & Secundaria & 3 & 6 & 9 & 9 & 14 & 8 \\
\hline & Superior & 0 & 1 & 1 & 2 & 4 & 2 \\
\hline & Sub-total & 100 & 100 & 100 & 100 & 100 & 100 \\
\hline \multirow{5}{*}{$\begin{array}{c}\text { Industrias } \\
\text { manufactureras }\end{array}$} & Primaria & 45 & 48 & 39 & 26 & 25 & 37 \\
\hline & Escolar Básica & 26 & 20 & 21 & 21 & 20 & 22 \\
\hline & Secundaria & 23 & 25 & 32 & 37 & 35 & 30 \\
\hline & Superior & 6 & 7 & 9 & 16 & 20 & 11 \\
\hline & Sub-total & 100 & 100 & 100 & 100 & 100 & 100 \\
\hline \multirow{5}{*}{$\begin{array}{c}\text { Electricidad, Gas y } \\
\text { Agua }\end{array}$} & Primaria & 12 & 22 & 21 & 5 & 7 & 13 \\
\hline & Escolar Básica & 13 & 21 & 6 & 17 & 8 & 13 \\
\hline & Secundaria & 52 & 28 & 35 & 25 & 19 & 32 \\
\hline & Superior & 24 & 29 & 38 & 53 & 67 & 42 \\
\hline & Sub-total & 100 & 100 & 100 & 100 & 100 & 100 \\
\hline \multirow{5}{*}{ Construcción } & Primaria & 62 & 64 & 53 & 46 & 42 & 53 \\
\hline & Escolar Básica & 25 & 20 & 24 & 25 & 22 & 23 \\
\hline & Secundaria & 10 & 13 & 19 & 24 & 28 & 19 \\
\hline & Superior & 4 & 3 & 4 & 5 & 8 & 5 \\
\hline & Sub-total & 100 & 100 & 100 & 100 & 100 & 100 \\
\hline \multirow{5}{*}{$\begin{array}{c}\text { Comercio, Restaurantes } \\
\text { y Hoteles }\end{array}$} & Primaria & 44 & 45 & 35 & 29 & 25 & 35 \\
\hline & Escolar Básica & 21 & 18 & 18 & 19 & 17 & 19 \\
\hline & Secundaria & 26 & 29 & 34 & 36 & 36 & 32 \\
\hline & Superior & 9 & 7 & 14 & 16 & 22 & 14 \\
\hline & Sub-total & 100 & 100 & 100 & 100 & 100 & 100 \\
\hline \multirow{5}{*}{$\begin{array}{c}\text { Transporte, } \\
\text { Almacenamiento y } \\
\text { Comunicaciones }\end{array}$} & Primaria & 33 & 45 & 28 & 20 & 21 & 29 \\
\hline & Escolar Básica & 22 & 16 & 15 & 18 & 16 & 18 \\
\hline & Secundaria & 30 & 29 & 37 & 40 & 36 & 34 \\
\hline & Superior & 14 & 10 & 20 & 22 & 27 & 19 \\
\hline & Sub-total & 100 & 100 & 100 & 100 & 100 & 100 \\
\hline \multirow{5}{*}{$\begin{array}{c}\text { Finanzas, Seguros e } \\
\text { Inmuebles }\end{array}$} & Primaria & 21 & 17 & 11 & 11 & 10 & 14 \\
\hline & Escolar Básica & 13 & 11 & 7 & 8 & 7 & 9 \\
\hline & Secundaria & 23 & 31 & 31 & 32 & 23 & 28 \\
\hline & Superior & 42 & 41 & 50 & 50 & 60 & 49 \\
\hline & Sub-total & 100 & 100 & 100 & 100 & 100 & 100 \\
\hline \multirow{5}{*}{$\begin{array}{l}\text { Servicios sociales, } \\
\text { comunales y } \\
\text { personales }\end{array}$} & Primaria & 42 & 41 & 33 & 23 & 21 & 32 \\
\hline & Escolar Básica & 18 & 14 & 12 & 13 & 13 & 14 \\
\hline & Secundaria & 21 & 22 & 24 & 26 & 24 & 23 \\
\hline & Superior & 20 & 23 & 30 & 38 & 43 & 31 \\
\hline & Sub-total & 100 & 100 & 100 & 100 & 100 & 100 \\
\hline
\end{tabular}

Fuente: Dirección General de Estadística, Encuestas y Censos - Encuestas de hogares 1997-8, 2002, 2007, 2002, 2012, 2017. Elaboración propia. 
Como indica el gráfico 3, en todas las ramas de actividad la media de escolarización de la población económicamente activa se incrementó, de modo que las ramas que cuentan con los perfiles más altos son las de electricidad, agua y gas, así también la de transporte, almacenes y comunicaciones, la de servicios sociales, comunales y personales, así como la de finanzas, seguros e inmuebles, la que de hecho es la de mayor nivel de formación de la fuerza laboral. La industria manufacturera, así como la construcción y, la rama de comercio, hotelería y restaurantes, presentan perfiles similares que no implican bajos niveles de escolaridad, pero cuya productividad y competitividad aún es baja, habida cuenta que en general constituyen las ramas generadoras de mayor valor agregado.

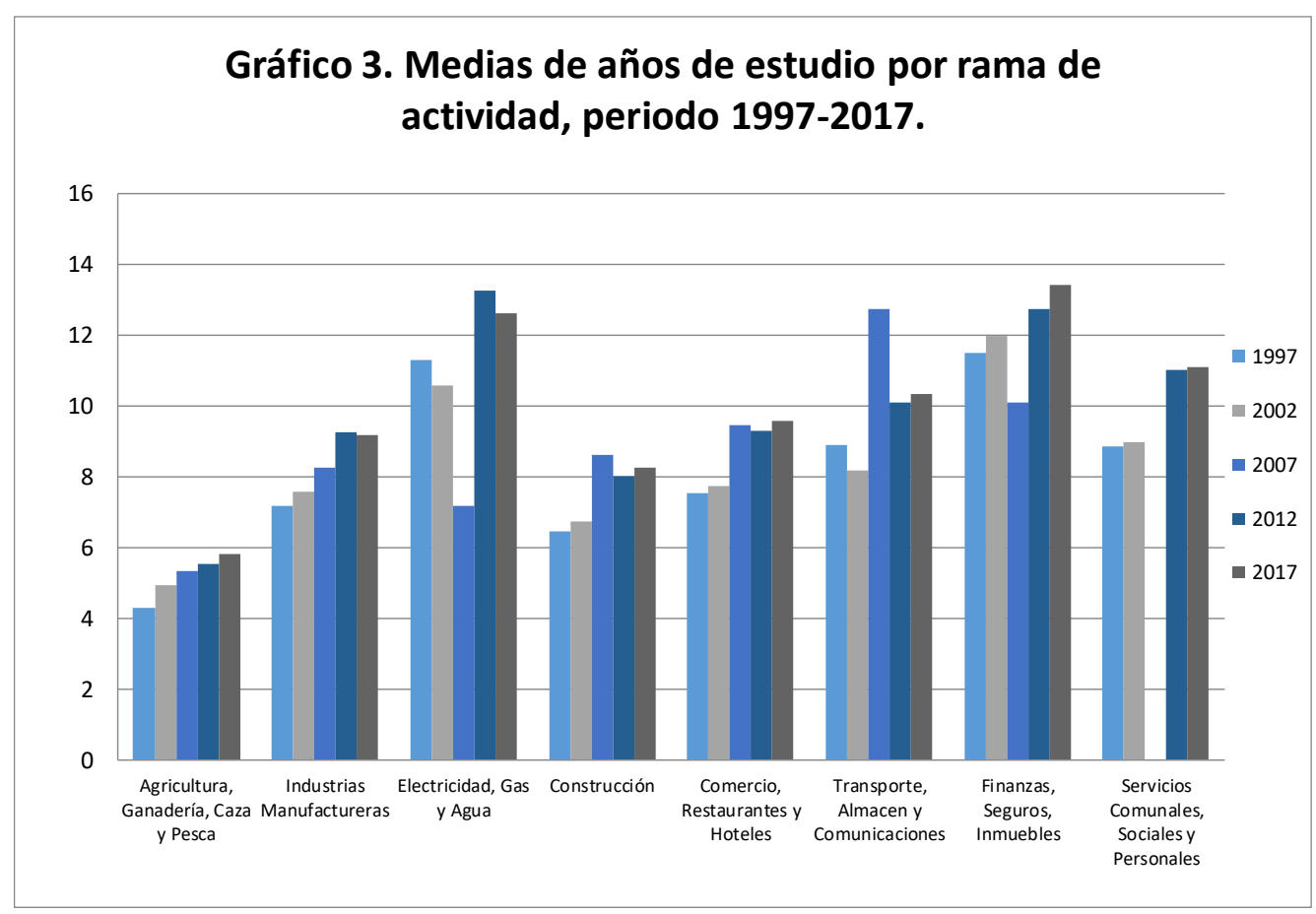

Fuente: Elaboración propia con base en encuestas de hogares 1997-2017, DGEEC.

Entre 1997 y 2017, la distribución de la población económicamente activa por nivel educativo, en cada rama de actividad económica, tomó las siguientes características. En la rama de agricultura, ganadería, caza y pesca, prevaleció el nivel de educación primaria durante todo el periodo, representando una media del $76 \%$. En la rama de industrias manufactureras, entre los años 1997 y 2007 sobresalió la fuerza laboral con nivel de educación primaria y en la última década, la del nivel secundario.

En la rama de electricidad, gas y agua se constata que solo en el año 1997 sobresalió la fuerza laboral con nivel secundario tomando impulso hacia el nivel superior desde el 2002 hasta el 2017. En la rama de la construcción sobresalieron los trabajadores con escolaridad primaria en todo el período.

En la rama de transporte, almacenamiento y comunicaciones, en los años 1997 y 2002 prevaleció la fuerza laboral con escolaridad primaria, mientras que, en los años 2007, 2012 y 2017 sobresalieron los trabajadores con nivel secundario.

En la rama de comercio, restaurantes y hoteles, durante el periodo comprendido entre los años 1997, 2002 y 2007 sobresalió la fuerza laboral con nivel de educación primaria, mientras que, en 2007, 2012 y 2017 se incrementó la población con nivel secundario de educación.

En la rama de finanzas, seguros, inmuebles, en todo el período (1997-2017) prevaleció la fuerza laboral con nivel de formación equivalente al egreso de la educación superior. Finalmente, en la rama de servicios sociales, comunales y personales, en los años 1997, 2002 y 2007, sobresale la fuerza laboral con nivel de educación primaria y, en la última década, se incrementó la población con nivel educativo secundario. 


\section{Aproximación a la absorción de la población trabajadora (demanda laboral).}

Este apartado presenta los rasgos de la cualificación de la población trabajadora contrastando el volumen demográfico, los niveles de escolaridad (años de estudio) y los ingresos per cápita, en función del tamaño de empresa donde la población económicamente activa desenvuelve su ocupación principal. En el mercado de trabajo paraguayo sobresale, como se constata en el cuadro 6 , la demanda de trabajadores de las microempresas y pequeñas empresas que, en su conjunto, representan en promedio el 83\% en el período de 1997-2017.

Cuadro 6. Distribución porcentual de la demanda laboral según tamaño de empresa, período 1997 - 2017

\begin{tabular}{|l|r|r|r|r|r|r|}
\hline $\begin{array}{c}\text { Tamaño de } \\
\text { empresas }\end{array}$ & 1997 & 2002 & 2007 & 2012 & 2017 & Promedio \\
\hline Micro y pequeñas & 93 & 89 & 88 & 72 & 75 & 15 \\
\hline Medianas & 5 & 4 & 5 & 12 & 16 & 10 \\
\hline Grandes & 3 & 7 & 7 & 16 & 9 \\
\hline Total & 100 & 100 & 100 & 100 & 100 & 100 \\
\hline \hline
\end{tabular}

Fuente: Dirección General de Estadística, Encuestas y Censos - Encuestas de hogares 1997-8, 2002, 2007, 2002, 2012, 2017. Elaboraci

Si nos aproximamos a la demanda a través del tamaño de empresa, observamos (cuadro 7) que las microempresas y las pequeñas empresas son aquellas donde se concentra la mayor proporción de trabajadores, que en 1997 alcanza el $93 \%$ de la totalidad de la población económicamente activa ocupada, en 2002 el 87\%, en 2007 el $88 \%$, en 2012 el $72 \%$ y en 2017 el $75 \%$ de participación. Ahora bien, a pesar de absorber predominantemente el empleo, la tendencia a la disminución de la proporción de la fuerza laboral en esos tipos de establecimientos da cuenta de un cambio en la estructura productiva que se traduce en el aumento relativo de inversión de capital en establecimientos medianos y grandes, lo que exige, como se verá más adelante, un mayor nivel de cualificación de la población trabajadora y un mayor nivel de retribución al trabajo.

Cuadro 7. Perfil de la demanda laboral según tamaño de empresa y sexo, periodo 1997-2017.

\begin{tabular}{l|l|r|r|r|r|r}
\hline $\begin{array}{l}\text { Tamaño de } \\
\text { empresas }\end{array}$ & \multicolumn{1}{c|}{ Sexo } & $\mathbf{1 9 9 7}$ & $\mathbf{2 0 0 2}$ & $\mathbf{2 0 0 7}$ & $\mathbf{2 0 1 2}$ & $\mathbf{2 0 1 7}$ \\
\hline \multirow{2}{*}{$\begin{array}{l}\text { Micro y } \\
\text { pequeñas }\end{array}$} & Hombres & 910,244 & $1,083,999$ & $1,206,881$ & $1,294,869$ & $1,364,692$ \\
\cline { 2 - 7 } & Mujeres & 440,266 & 517,177 & 642,120 & 825,084 & 769,739 \\
\hline \multirow{2}{*}{ Medianas } & Hombres & 113,342 & 112,350 & 172,759 & 238,066 & 201,126 \\
\cline { 2 - 7 } & Mujeres & 53,063 & 68,793 & 96,600 & 133,758 & 120,316 \\
\hline \multirow{2}{*}{ Grandes } & Hombres & 199,409 & 144,760 & 138,916 & 208,588 & 276,900 \\
\cline { 2 - 7 } & Mujeres & 55,956 & 187,004 & 233,121 & 292,312 & 154,155 \\
\hline Total & & $\mathbf{1 , 7 7 2 , 2 8 0}$ & $\mathbf{2 , 1 1 4 , 0 8 3}$ & $\mathbf{2 , 4 9 0 , 3 9 7}$ & $\mathbf{2 , 9 9 2 , 6 7 7}$ & $\mathbf{2 , 8 8 6 , 9 2 8}$ \\
\hline \hline
\end{tabular}

Fuente: Dirección General de Estadística, Encuestas y Censos - Encuestas de hogares 1997-8, 2002, 2007, 2002, 2012, 2017. Elaboracić

Algunos estudios afirman que los factores que empujan a las empresas u organizaciones a contratar (o no) más profesionales son: la demanda del producto o servicio, las expectativas de crecimiento del establecimiento y el nivel formativo de los puestos directivos. Además, el tamaño de la empresa indica las necesidades de personal dependiendo de los cambios en la productividad, por la incorporación de tecnología, la disponibilidad interna y externa de recursos financieros y el número de trabajadores en el establecimiento. 
Dado un aumento en la productividad, generado por un cambio en tecnología, se espera un menor requerimiento de personal para cada unidad de producción, pero debido al incremento de la productividad el precio del producto o servicio tiene a reducirse, con el consecuente aumento de su demanda y en consecuencia la rentabilidad será el resultado de la escala de producción, generando las condiciones para el aumento de personal demandado y por lo tanto del número de trabajadores en el establecimiento, es decir, el tamaño de la empresa (Cerrato Reyes; Argueta; Zavala, 2017).

Lo que no está claro en este esquema es el efecto sobre los ingresos habida cuenta de la sobreoferta laboral disponible en el mercado de trabajo (Ortiz, 2005).

En el gráfico 4 se puede observar que la media porcentual de la población ocupada en las microempresas y pequeñas empresas es casi cinco veces más que la población ocupada en las empresas medianas y grandes, aunque ha habido una disminución de la proporción de la PEA en las primeras y aumento en las segundas.

Este fenómeno es posiblemente resultante de la mayor inversión de capital en el país y del aumento concomitante de la escolarización en la población económicamente activa, disminuyendo relativamente la brecha.

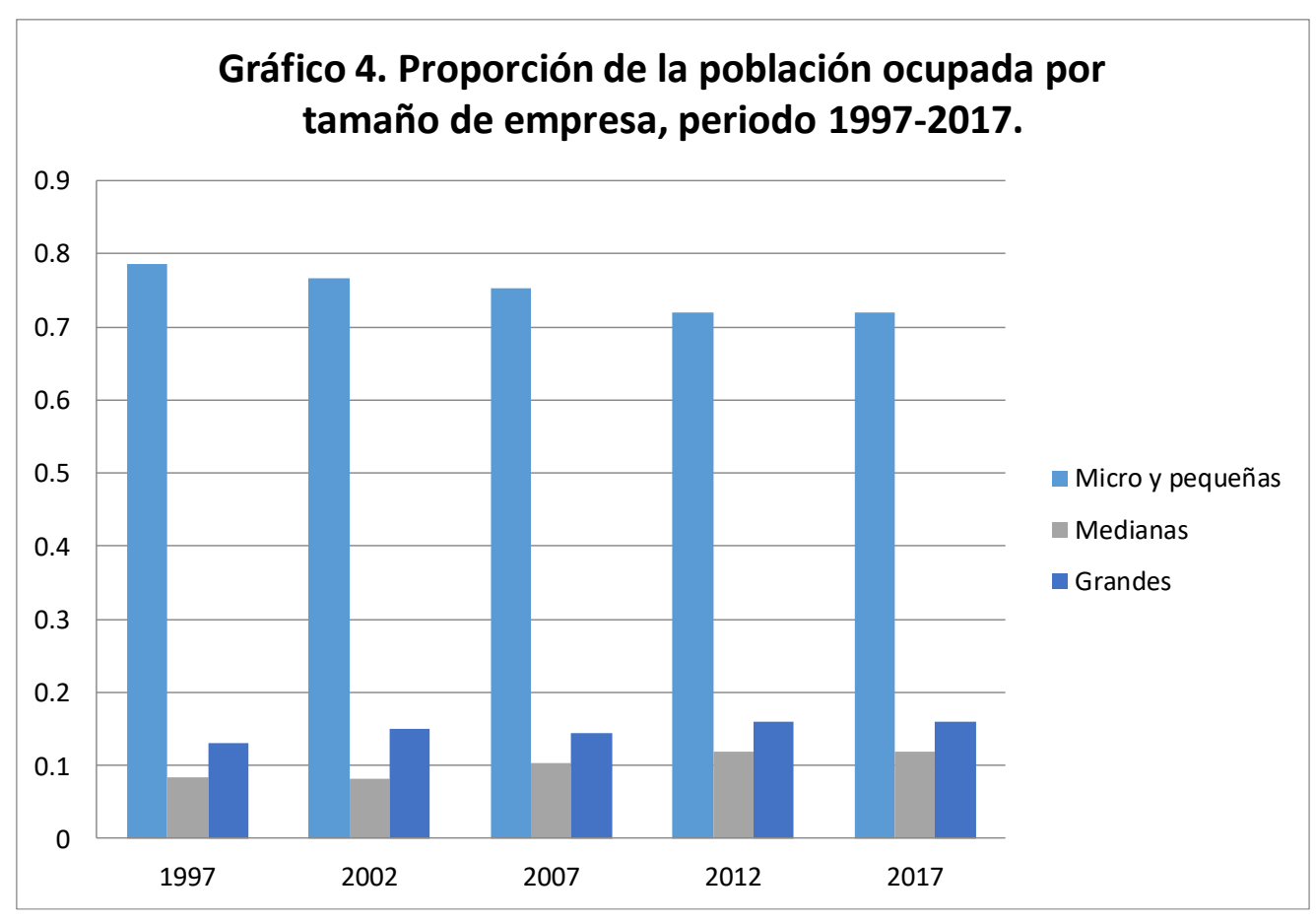

Fuente: Elaboración propia con base en encuestas de hogares 1997-2017, DGEEC.

En el gráfico 5, donde se ilustra la evolución de la participación laboral por sexo según los tipos de establecimientos, se observa que las microempresas y las pequeñas concentran el mayor número de población femenina como fuerza laboral, sobrepasando la cantidad de la población trabajadora masculina en los años 1997 y 2002, equiparándola en el año 2007, pero declinando y cediendo espacio en los años 2012 y 2017.

En las medianas empresas, empero, predomina la participación laboral masculina durante todo el periodo: la brecha se redujo parcialmente solamente en el 2002, cuando representó únicamente 48.615 trabajadores de diferencia. Ahora bien, las mujeres representaron, durante casi todo el periodo, la proporción más elevada de la participación laboral en las grandes empresas, donde superan a los trabajadores entre el 2002 y el 2012, decayendo en el último quinquenio cuando aumentó la proporción masculina al año 2017. 


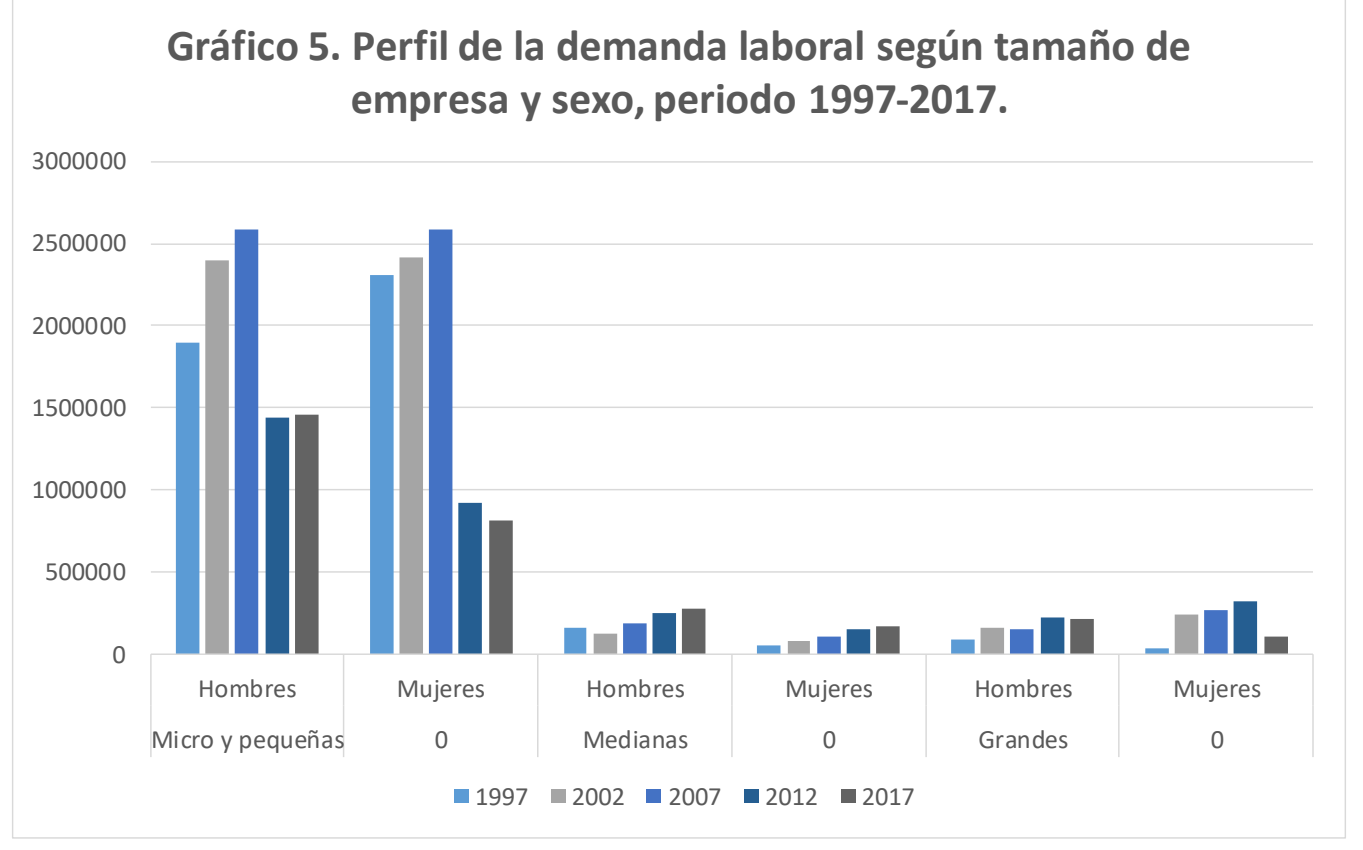

Fuente: Elaboración propia con base en encuestas de hogares 1997-2017, DGEEC.

La demanda laboral según el rango etario (gráfico 6) se caracterizó durante el periodo por el hecho que, salvo entre las microempresas y las pequeñas empresas, los establecimientos siguen el patrón de menor contratación de adolescentes (10 a 17 años) y mayor contratación de población adulta (25 a 64 años).

Como ya se refirió en la sección anterior, la tendencia a la menor participación de la población juvenil (y adolescente) en la fase que siguió a la expansión de la escolarización, se explica por la absorción progresiva de la población en edad escolar por el sistema educativo (Borda et al., 2015), sentando las bases sociodemográficas de nuevos rasgos del mercado de trabajo a partir de inicios del siglo XXI.

En consecuencia, los establecimientos económicos de envergadura (medianos y grandes), conformantes casi por definición del segmento formal del mercado de trabajo, evitan la contratación de jóvenes menores de edad, tanto por las restricciones de la legislación sobre la infancia y la adolescencia, que cobró fuerza en la primera década del dos mil, como por los requerimientos de cualificación y productividad que esperan de un rango etario adulto, que dispone de titulación de la educación superior.

Por su parte, los trabajadores adultos (de entre 25 y 64 años) representan la mayor proporción de la fuerza laboral tanto para las microempresas y pequeñas empresas, como para medianas y grandes.

Cabe además resaltar que tendencias incrementales se notan únicamente en las medianas empresas en donde la participación laboral de adultos crece de aproximadamente 100.000 trabajadores en 1997 hasta alcanzar aproximadamente 350.000 trabajadores en 2017. 


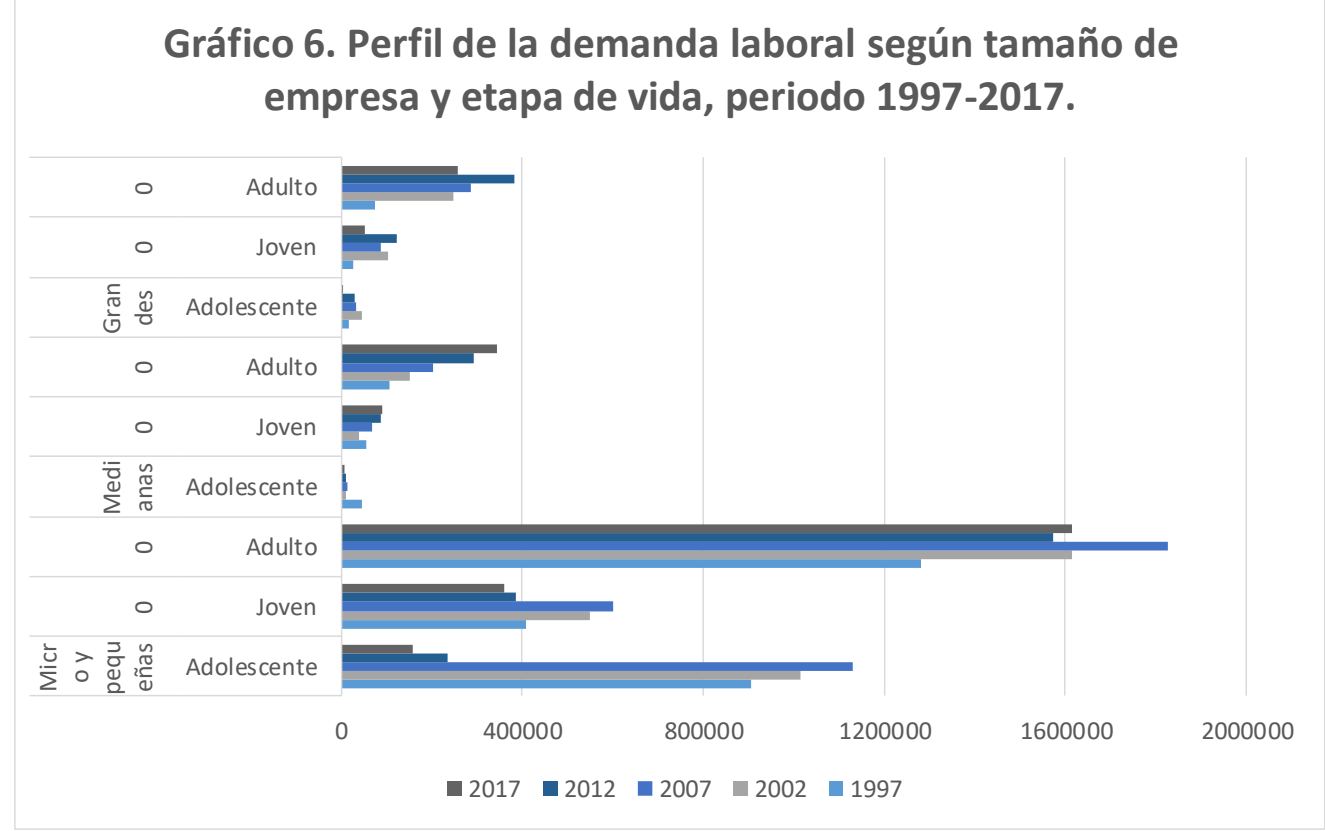

Fuente: Elaboración propia con base en encuestas de hogares 1997-2017, DGEEC.

Respecto a los ingresos medios de la población trabajadora, la tendencia según el tamaño de las empresas ha sido, durante el periodo, de una menor retribución en las microempresas y pequeñas aun si atravesaron un proceso de aumento medio de las retribuciones al personal, mientras que los ingresos en las medianas y grandes empresas tuvieron comportamientos disímiles: la PEA en las medianas empresas tuvo una relativa mayor remuneración hasta el quinquenio 2007-2012, cuando la población trabajadora en las grandes empresas aumentaron sus medias de ingresos, otra forma en que ciertos cambios en la estructura económica paraguaya se están dando en términos de la composición de la PEA.

La distribución de los tipos de establecimientos según el nivel de ingreso de los trabajadores se caracteriza por la concentración de la población trabajadora con retribuciones inferiores al millón de guaraníes, en las microempresas y pequeñas empresas, durante todo el periodo de estudio (gráfico 7) pero se constata también que, durante dicho lapso, ese tipo de establecimientos atravesó una tendencia decreciente de la cantidad de trabajadores que recibe el menor rango de ingresos.

Como refieren Borda y otros, para el periodo 1997-2008, "a diferencia de las grandes empresas, las de menor tamaño se caracterizan por su menor nivel de productividad, el uso de tecnología simple, poca concentración de capital, creación de empleos de bajo costo y demanda de recursos humanos con baja calificación profesional. Por lo tanto, es esperable que este cambio en la composición por tamaño de los establecimientos haya tenido efectos sobre los ingresos de los trabajadores" (Borda, González y otros, 2011, p. 54).

Sin embargo, esta disminución proporcional de trabajadores con menores ingresos no es aún, al final del periodo, superada por la proporción de trabajadores con mayores niveles de ingreso, como sí es el caso entre las medianas y grandes empresas. Además, la población trabajadora con niveles de ingresos entre dos y cuatro millones de guaraníes experimentó un crecimiento importante, tanto a nivel de medianas como grandes empresas: entre 2007 y 2017 casi se cuadruplica en las medianas empresas mientras que se triplica en las grandes empresas.

En contrapartida, desde el año 2007 las medianas empresas concentran mayor proporción de población trabajadora en el segmento de ingresos entre uno y dos millones de guaraníes. El mismo tipo de empresas, en el año 2017, concentra la mayor proporción de trabajadores en el rango de ingresos de entre dos y cuatro millones de guaraníes, que implica el nicho de la demanda laboral con mayores niveles de ingresos. 


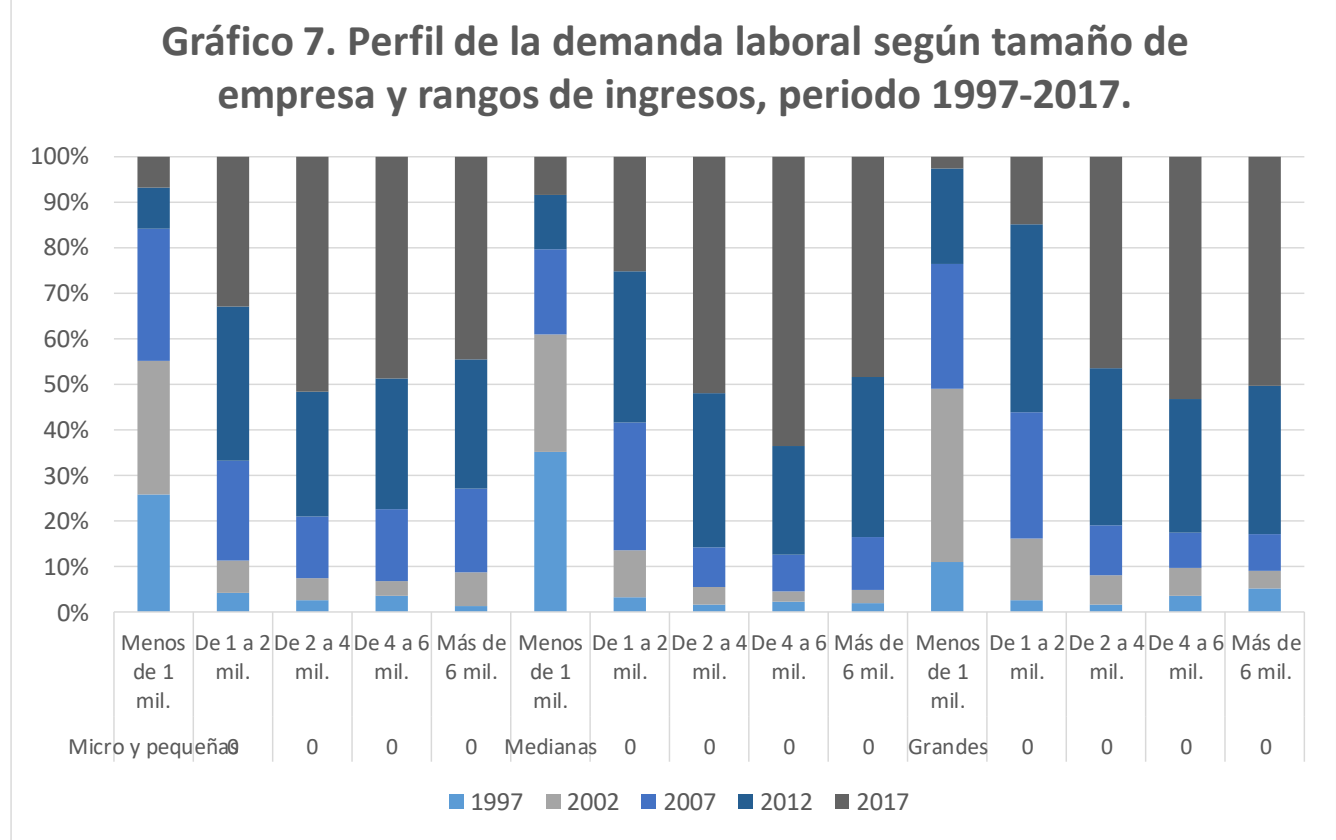

Fuente: Elaboración propia con base en encuestas de hogares 1997-2017, DGEEC.

En lo que a los niveles educativos de la población según el porte de los establecimientos económicos concierne, se observa en el gráfico 8 que las microempresas y pequeñas empresas presentan las medias de escolarización inferiores entre su población empleada, pasando de 4,2 años de estudio en 1997 a 8,1 años de estudio en 2017, es decir se duplicó la media de escolaridad en esos tipos de establecimiento, quedando bajo de las medianas y grandes empresas.

Mientras las microempresas y pequeñas empresas se caracterizan por emplear a trabajadores con menor nivel educativo, las medianas empresas concentran la mayor proporción de trabajadores del nivel educativo superior, o sea, con mayor cualificación técnica y profesional, tendencia histórica que resulta en una convergencia del nivel de escolaridad entre las empresas de mediano y las de elevado porte en el año 2017 y con perspectivas de invertirse, es decir, estas últimas en proceso de absorber población trabajadora con el mayor nivel educativo. Este es otro indicador del leve y paulatino cambio que la estructura económica está experimentando.

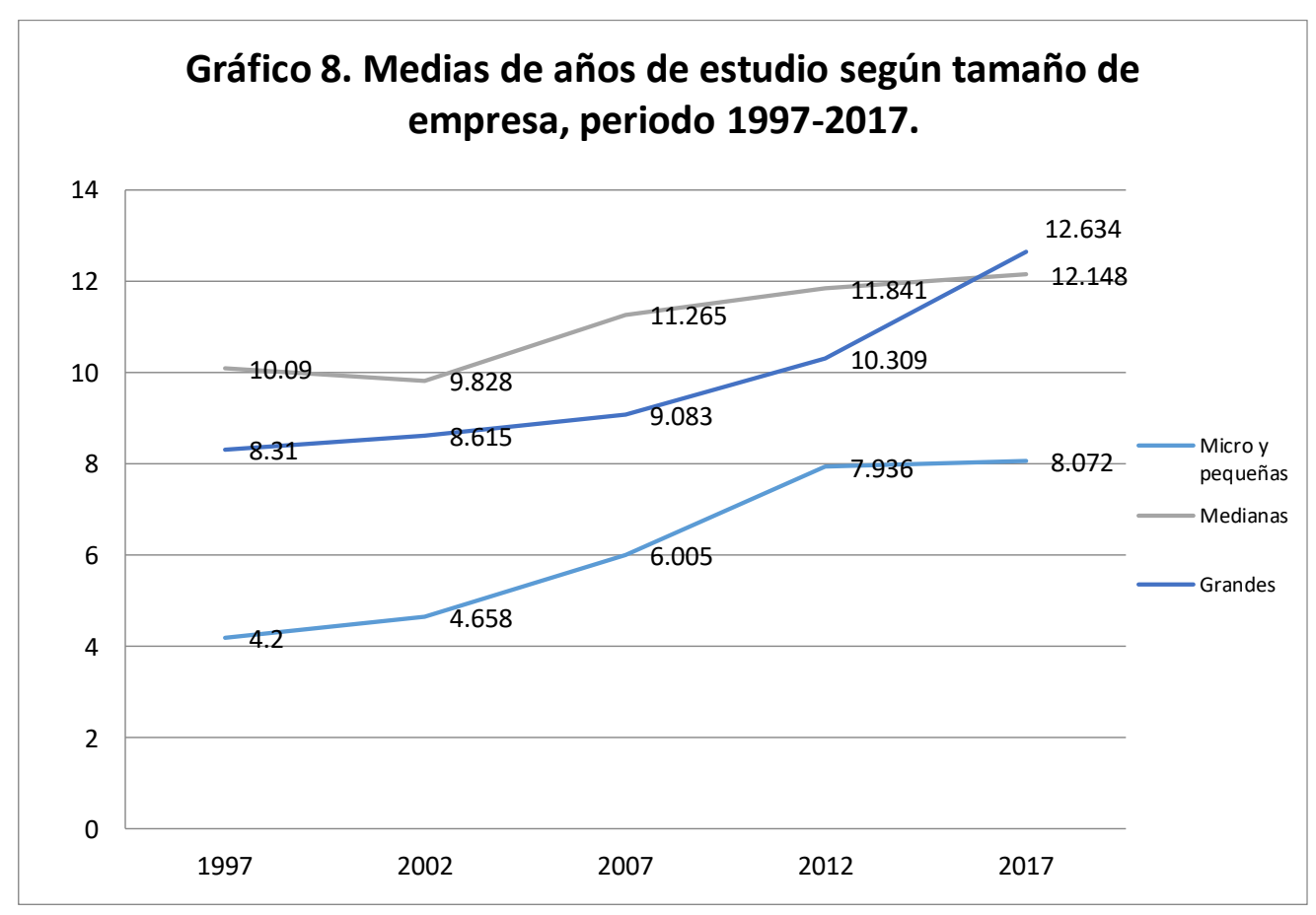

Fuente: Elaboración propia con base en encuestas de hogares 1997-2017, DGEEC. 
Si bien la tendencia de la demanda respecto de la cualificación de la fuerza laboral comportó en todos los tipos de empresas una disminución de la población absoluta con bajos niveles educativos y el aumento de población con niveles intermedios y superiores, al contar con la mayor proporción de población empleada, las microempresas y pequeñas empresas absorben también en números absolutos la mayor cantidad de población trabajadora titulada de la educación superior. Aquí el problema radica en las características de calidad y eficacia de la educación, ya que si, de caracterizarse las microempresas y pequeñas empresas por altos niveles de ingresos concomitantemente con los altos niveles de escolaridad que fueron adquiriendo sus planteles progresivamente, la tendencia hubiera dado cuenta de la fuerza de este tipo de establecimientos en el producto, de alta productividad y competitividad.

Sin embargo, esta asociación no se constata, de modo que, como indica Fanelli, "alrededor de la mitad de las empresas considera a la calificación de la fuerza laboral como una restricción relevante, la cual (sin embargo) está por encima del promedio tanto mundial como regional (...) Cuando la calificación es deficiente, la capacidad de absorción de tecnologías y de adaptación a nuevas formas organizacionales es reducida" (Fanelli, 2012, pp. 25-26).

Las características de las empresas según los niveles de estudio de la población económicamente activa presentan tres principales aristas: en lo que respecta a las microempresas y pequeñas empresas, la participación de trabajadores con escolaridad equivalente a educación primaria disminuyó progresivamente en el periodo, pero en el 2017 este tipo de establecimientos económicos contrata todavía, preponderantemente, trabajadores con un nivel educativo básico sin siquiera, en una proporción considerable, haber iniciado la educación secundaria. Contrariamente, el nivel educativo de trabajadores con educación superior (terciaria o universitaria) representa la mayor proporción tanto para el tipo de medianas y grandes empresas.

Si bien los establecimientos de mediano y gran porte se expandieron en el periodo de 1997-2017, sus pesos proporcionales en la estructura económica son reducidos, involucrando entre ambos, para el 2017, menos de la mitad de trabajadores de los primeros considerados conjuntamente.

Sin embargo, el incremento de trabajadores con un nivel educativo de educación superior fue de diez veces entre 1997 y 2017 en las medianas empresas, mientras que, en las grandes empresas, el aumento en cuestión durante el mismo periodo fue de siete veces, de modo que en estos tipos de empresa dicho perfil de trabajadores se convirtieron en los más representativos, dando lugar a una tendencia de mayor productividad del trabajo y mayor competitividad de la gestión en el seno de los establecimientos.

En términos de las medias del ingreso laboral de la ocupación principal, el mercado laboral paraguayo se caracteriza por un crecimiento lento del ingreso medio entre los años 1997 y 2017, que alcanzó a aumentar 4 veces solamente respecto a la media de hace 20 años.

La situación del bajo ingreso medio en la rama de actividad correspondiente a Agricultura, Ganadería, Caza y Pesca se debe principalmente a la dualidad de la productividad en la estructura agraria, con la coexistencia de un sector social productivo con acceso al capital y que canalizó importantes facilidades de inversión, con un sector productivo de escasa capitalización y que con bajos niveles de inversión pudo satisfacer sus necesidades sociales básicas con los ingresos familiares que se hacen plausibles para dicho propósito a través de la contribución de todos los miembros en el trabajo predial para hogares de tamaños superiores a la media nacional.

A esta característica se suma el nivel medio de educación más precario de los trabajadores, que alcanza para el año 2017 apenas el equivalente a 6 años de estudio, marcadamente inferior a la media nacional para el mismo año, que alcanzó los 9 años de estudio. Este hecho, a saber, el de los bajos niveles de retribución al trabajo en el sector agropecuario no se condice con el elevado crecimiento del producto -como se verificó en el cuadro 1-, expresando una fuerte concentración del ingreso.

Ésta rama, junto con la de la construcción, con una media de 8 años de estudio entre los trabajadores, concentran la fuerza laboral con formación educativa más baja de la PEA ocupada. Sin embargo, en términos de las retribuciones laborales, la rama de Agricultura, Ganadería, Caza y Pesca es donde se obtienen las medias de ingreso más reducidas, seguida de la rama de Comercio, Restaurantes y Hoteles, asumiendo el fenómeno un carácter marcado en el año 2017.

La tendencia de la estructura económica, particularmente la demanda laboral, es la paulatina incorporación de capital -en especial tecnológico- en los procesos productivos y distributivos, requiriendo concomitantemente un aumento de la población de medio y alto nivel educativo, que se hizo posible, en mayor ritmo, con el aumento de la escolaridad media en la población paraguaya a partir de la reforma educativa en los años noventa. 
Esto, a su vez, está asociado al proceso de aumento de la inversión directa en ramas de la actividad de los tres sectores de la economía, aunque el peso más elevado se constata en el sector primario y el terciario de la economía. Entre estos últimos, las empresas tienen tamaños heterogéneos, acentuándose un fenómeno constatado por Albert Berry a finales de la década del 2000, a saber, que la economía paraguaya concentra las actividades en empresas pequeñas donde se ocupa la mayor proporción de la población económicamente activa (Berry, 2012).

La inversión de capital, sin embargo, no constituye aun la regla en el desarrollo de la estructura económica dada la persistencia de instituciones que ponen freno al aumento de la productividad y de la competitividad tales como la informalidad laboral, la inseguridad jurídica, la inequidad fiscal respecto a los establecimientos que invierten, adoptan tecnología y contratan fuerza laboral en comparación con aquellos cuya inversión es irrisoria, no transfieren tecnología y contratan baja proporción de fuerza laboral.

De este modo, no se avizora aun un viso de cambio del régimen flexible de contratación laboral -dada una población desempleada o subempleada que presiona por el acceso al empleo formal y empuja los salarios hacia la baja- y del bajo nivel de incentivo de la población a elevar sus niveles educativos. Esto es más crítico entre los sectores sociales desfavorecidos que se ven obligados a la deserción y dimisión escolar para ingresar tempranamente al mercado de trabajo, engrosando el segmento informal y dando lugar a un círculo vicioso de reproducción de las condiciones económicas desfavorables para el desarrollo productivo y el acceso al bienestar.

\section{CONCLUSIÓN}

El impacto del proceso de masificación educativa y de la inflación de los diplomas -especialmente universitarios-en la estructura socioocupacional fue la producción de una nueva forma de desigualdad social, que persistió en el periodo porque los nichos de menor productividad y competitividad contaron con bajos volúmenes de capital, reforzando su rezago al no apuntalar las cualificaciones que conllevó una inflación credencialista sin efecto sobre el valor agregado y sobre el aumento a la retribución del trabajo.

Este problema conocido como la heterogeneidad estructural constituye el principal factor limitante para el desarrollo económico en general y de productividad del trabajo en particular. La productividad se dispersa en enclaves competitivos que por lo general tienen una orientación exportadora mientras que la mayoría de las ramas de actividad económica alberga bajos niveles de capacidad productiva.

La dualidad de este proceso empieza a generar una crisis social, traducida en las acciones colectivas de una sociedad civil que accedió a las credenciales ofrecidas por la reforma educativa pero que se vio restringida en el acceso al segmento formal del mercado de trabajo debido a los requerimientos de la demanda laboral para "abrir" las puertas de acceso.

En una estructura económica heterogénea y de productividades dispersas, la desigualdad social es un hecho estructural que difícilmente se revierte si no interviene la acción pública. De no corregirse esta tendencia, el mercado continuará prevaleciendo en la distribución de los incentivos y las sanciones con la consecuente devaluación de bienes públicos como la educación.

El rasgo principal de la población económicamente activa, afectado por la inflación credencialista, es su desfase de los requerimientos del segmento formal del mercado de trabajo que estipula crecientes exigencias profesionales para controlar el acceso a los escasos puestos de mayor productividad.

El sistema educativo, en consecuencia, no se instituye como un factor determinante, que rompe con el círculo vicioso, sino que lo mantiene, con baja calidad de la enseñanza, ineficacia en el aprendizaje y deficiencia de la infraestructura. En efecto, la sociedad paraguaya aumentó su población titulada para acceder al segmento formal del mercado de trabajo, sin embargo, éste fue limitado en acoger la oferta laboral.

\section{BIBLIOGRAFÍA}

1. Berry A. et al. (2017), Losing ground in the employment challenge: The case of Paraguay, New York: Routdledge Taylor \& Francis Group.

2. Berry A. (2012). Productividad, diversidad y crecimiento económico incluyente. En Abente Diego y Borda Dionisio, Los retos del futuro. Asumiendo los legados del Bicentenario. Asunción: Ministerio de Hacienda. 
3. Bertranou F., Marinakis A. y Reinecke G. (2003). Mercado de trabajo, instituciones y pobreza: interrelaciones y desafíos en Paraguay, en Organización Internacional del Trabajo. Paraguay: Empleo y protección social. Desafíos institucionales para reducir la pobreza. Asunción: OIT.

4. Borda D., González C. y García D. (2015). Inserción de los jóvenes en el mercado de trabajo, Asunción: CADEP.

5. Borda D., González C., Ramírez J. y Perera M. (2011). Comportamiento del empleo e ingresos en el Paraguay. Análisis de una década (1997-2008). Asunción: CADEP.

6. Brunet I., Böcker Zavaro R. (2014). Competitividad, Competencias y Fin del Ciclo Fordista. International Journal of Sociology of Education, 3(1).

7. Carnoy M. et al. (1986), Economía política del financiamiento educativo en los países en desarrollo. México: Gernika.

8. CEPAL (2012). Productividad laboral y distribución, CEPAL/OIT, Santiago.

9. Cerrato Reyes, K., Argueta, L., y Zavala, J. (2017). Determinantes de la empleabilidad en el mercado laboral. Economía y Administración, 7(1).

10. Cortés F. (2016). Discusiones sobre desigualdad y clases sociales en América Latina en los albores del siglo XXI. En L. Ortiz, Desigualdad y clases sociales. Estudios sobre la estructura social paraguaya. Asunción: CEADUC//CLACSO/ICSO.

11. Dirección General de Estadísticas, Encuestas y Censos-Paraguay (2018). Encuestas permanentes de hogares 1997, 2002, 2007, 2012, 2017, Data set recuperado de: http://www.dgeec.gov.py/microdatos/index.php

12. Fanelli J.M. (2012). Crecimiento y Equidad en Paraguay. Asunción: M.H. Disponible en: http://www.economia.gov.py/application/files/1514/6557/8804/Fanelli_Crecimiento_Equidad_Py.PDF

13. Goetz K. y Vázquez F. (2014). La intensificación de la urbanización en el Paraguay profundo: el despertar de las ciudades del interior, Revista de Investigación en Ciencias Sociales, 1(1).

14. Grootings P. (1994). De la cualificación a la competencia: ¿de qué se habla? Revista Europea de Formación Profesional, $\mathrm{N}^{\circ} 1$.

15. McConnell C. y Brue S. (2007). Economía Laboral. Madrid: McGraw Hill.

16. Ministerio de Trabajo, Empleo y Seguridad Social (2018). Principales Indicadores del Mercado Laboral. Asunción: MTESS.

17. Ortiz L. (2016). Apuntes para el estudio de las clases en la sociedad paraguaya. En Ortiz Luis, Desigualdad y clases sociales. Estudios sobre la estructura social paraguaya. Asunción: CEADUC-CLACSO-ICSO.

18. Ortiz L. (2014). La educación escolar en Paraguay. El sistema educativo ante los desafíos de la desigualdad. En Gregosz David, Los desafíos de educación preescolar, básica y media en América Latina. Santiago: KAS/SOPLA.

19. Ortiz L. (2005). Las estructuras sociales del empleo. En Asociación Paraguaya de Estudios de Población, Algunos enfoques sobre el empleo y el capital social. Resultados de investigaciones, Asunción: UNFPA/ADEPO.

20. Schiefelbein E. (2007), Educación y empleo en el Paraguay. en Borda Dionisio y Masi Fernando. Economía y Empleo en el Paraguay. Asunción: CADEP.

21. Serafini V. (2016). Clase, género y pobreza. Algunas ideas para el debate. En L. Ortiz, Desigualdad y clases sociales. Estudios sobre la estructura social paraguaya. Asunción: CEADUC/CLACSO/ICSO. 